\title{
VALPARAÍSO: EL DERECHO AL PATRIMONIO
}

\author{
Valparaíso: the right to heritage
}

\author{
MAURICIO ROJAS ALCAYAGA* \\ VICTORIA BUSTOS URBINA**
}

Fecha de recepción: 15 de marzo de 2015 - Fecha de aprobación: 30 de abril de 2015

\section{Resumen}

La organización social que se ha conformado en torno a la defensa del patrimonio cultural, tangible e intangible, sin duda constituye una de las transformaciones más significativas de los denominados movimientos urbanos. Este trabajo aborda una de las experiencias más significativas y paradigmáticas de este fenómeno en Chile: los movimientos de defensa patrimonial en Valparaíso. Ciudad en la cual su casco histórico fue declarado Patrimonio de la Humanidad por UNESCO, y cuya propia declaratoria reveló las contradicciones sociales y políticas en relación a su valoración y protección, lo que, paradójicamente, estimuló el fortalecimiento de movimientos patrimonialistas. Comprender los orígenes, las motivaciones, orientaciones y objetivos de éstos es el principal propósito de este artículo, y de esta manera, contribuir desde las ciencias sociales a profundizar el análisis crítico de los problemas de la cultura urbana, partiendo de la base conceptual que la ciudad y su patrimonio se ha constituido en un derecho de todos.

Palabras clave: patrimonio, ciudad, derecho, sociocultural, movimientos urbanos.

\section{Abstract}

The social organization that has taken shape around the defense of tangible and intangible cultural heritage undoubtedly constitutes one of the most significant transformations among urban movements. This work addresses one of the most important and paradigmatic examples of this phenomenon in Chile: movements that defend cultural heritage in Valparaiso. UNESCO's own declaration about Valparaíso's historic quarter as a World Heritage Site, revealed the social and political contradictions surrounding the city's value and protection and paradoxically, stimulated the strengthening of cultural heritage movements. The principal goal of this article is to understand the origins, motivations, orientations, and objectives of these movements, thus contributing to and deepening the critical analysis of problems in urban culture from a social sciences perspective, starting from the conceptual base that everyone has a right to cities and their heritage.

Keywords: heritage, city, right, sociocultural, urban movements.

\footnotetext{
* Doctor Ciencias Antropológicas, Docente Universidad Alberto Hurtado. Correo electrónico: mgrojas@uahurtado.cl, **Magíster en Estudios Sociales y Políticos Latinoamericanos, Universidad Alberto Hurtado.

Correo electrónico:victoriabustosurbina@gmail.com
} 


\section{Introducción}

Este artículo expone en perspectiva diacrónica y sincrónica a la vez, la dinámica social que se ha activado en Valparaíso desde hace alrededor de dos décadas por parte de diversas organizaciones sociales en pro de la defensa del patrimonio cultural en la ciudad puerto. El trabajo es fruto de dos investigaciones que se desarrollan a lo largo de diez años y que se articulan en torno a la continuidad y permanente reactualización de las luchas patrimoniales, las cuales han convertido a las asociaciones ciudadanas porteñas en un ícono de lo que hoy diversos especialistas denominan movimientos patrimonialistas, y cuyo surgimiento se explicaría esencialmente por el repliegue del Estado en materias de desarrollo cultural y protección del patrimonio, dejándolo al arbitrio de políticas neoliberales y globalizadoras (Salazar, 2006). Es indudable que estas asociaciones constituyen un conjunto variopinto de reivindicaciones y contradicciones respecto del problema urbano, y por ende, se ajustan a lo que Manuel Castells denomina movimientos sociales urbanos, a los cuales caracteriza como: "sistemas de prácticas sociales contradictorias que controvierten el orden establecido a partir de las contradicciones específicas de la problemática urbana" (2004:3).

En este contexto, un hecho importante a destacar es que, si bien las organizaciones patrimonialistas son parte de esta característica enunciada, y forman parte de importantes luchas de movimientos sociales urbanos, se distinguen $\mathrm{y}$ adquieren especificidad propia en la redefinición de lo sociopolítico. De este modo, estas organizaciones se podrían inscribir en lo que Garretón (2002) llama el mundo de las intersubjetividades, es decir, movimientos urbanos que apelan a problemas de la vida diaria, reconocimiento social o de identidades sociales. No desconocen lo político, pero desde el prisma de estas asociaciones este factor transita desde un orden político-económico hacia dimensiones mayoritariamente socioculturales, tales como problemas asociados a temas de género, étnicos y medioambientales (Calderón, 2009), a lo cual cabe agregar, sin duda alguna, el fenómeno patrimonial.

En el caso de Valparaíso son diversas las organizaciones de esta índole que se distribuyen por sus cerros y calles, que han luchado y lo siguen haciendo hasta hoy por sus barrios y territorios, destacando el hecho que no es el aspecto físico el que actúa como motivo principal, sino el imaginario social que lo constituye (Márquez, 2007), en la medida que lo comprenden como el escenario de la práctica cotidiana y de imaginarios en donde los individuos y colectividades establecen significaciones y prácticas económicas, políticas y culturales (Nivón, 1989). Y es esta concepción colectiva e identitaria lo que estimula la organización de vecinos y ciudadanos para que distintas zonas de Valparaíso, sean o no parte de la declaratoria patrimonial oficial, sean respetados y no se vean afectados por los agresivos proyectos inmobiliarios que responden a la lógica neoliberal (López-Morales, 2012) y no patrimonial, como asimismo que sean valorados por las autoridades locales, tanto como por la propia comunidad.

El artículo transcurre desde la paradigmática campaña "Que no nos tapen la vista" en los albores de este siglo, hasta la última y actual bataIla que se articula bajo la consigna ¡NO al mall Barón! Ambas representan un sentido de continuidad en la defensa patrimonial, unificadas por el rechazo que provoca el aparente contubernio entre el poder público y el poder privado para 
provocar modernizaciones urbanas de carácter capitalista, que más que proteger bienes patrimoniales pretenden buscar rentabilidades de mercado (Carrión, 2005; Pérez, 2013). En el primer caso las organizaciones patrimonialistas se opusieron tenazmente a la edificación en altura en el borde costero; y el segundo, representa el rechazo a la pretensión de la empresa privada de construir y edificar un mega centro comercial y un grupo de edificios en los terrenos de la Empresa Portuaria de Valparaíso (EPV) ${ }^{4}$, iniciativa que ha contado con el apoyo tanto de la autoridad local como del nivel central de la administración del Estado.

Para los movimientos patrimonialistas instalar un mall (centro comercial) en el borde costero y en las cercanías de la zona declarada Patrimonio Cultural de la Humanidad, es una decisión que se suma a muchas otras que atentan contra su identidad cultural, y su derecho de goce al patrimonio cultural como un bien público, democrático y colectivo. Esto sitúa a estas reivindicaciones socioculturales en la esfera de lo que Harvey (2013) denomina el "Derecho a la Ciudad", movimientos surgidos desde contextos cotidianos, que se hacen parte de un proceso de transformación de la vida cultural urbana, confrontando al modelo de ciudad dominado por el capital globalizado.

Entonces, bajo esta perspectiva, la ciudad se transforma en un campo de disputa en donde se produce una lucha por el control del espacio (Harvey, 2008). Esto genera las condiciones para que la ciudad misma se transforme en un ejercicio político, ya que se redefine el rol de la ciudadanía en la construcción material e imaginaria de las urbes en América Latina, considerando que la construcción de la ciudad debe incluir necesariamente a la sociedad en su conjunto, es decir, como un derecho de todos.
Y si la ciudad es de todos sus ciudadanos/as, es evidente que para una adecuada comprensión de sus problemas debe ser abordada incluyendo a sus protagonistas, a sus propios habitantes. Por este motivo, este trabajo se basa en un enfoque cualitativo que incorpora la voz de los protagonistas en su análisis, entendiendo que sólo de este modo es posible comprender en su magnitud más profunda el surgimiento de movimientos urbanos de carácter sociocultural, los cuales se organizan en torno al patrimonio para confrontar a un modelo urbano neoliberal, que bajo la lógica del mercado expropia a sus habitantes, en este caso a los porteños, al derecho a imaginar y habitar su ciudad.

\section{Los ciudadanos y el derecho a la ciudad}

La procedencia y constitución de estas agrupaciones urbanas de la sociedad civil de Valparaíso son diversas. En la mayoría de los casos representan el malestar de territorios determinados, sin embargo, uno de los hechos más innovadores en su constitución y accionar, es que sus reivindicaciones trascienden la inquietud particular de sus entornos, desencadenando una toma de conciencia del problema común del derecho a su ciudad, como un proceso insurgente al modelo neoliberal (Harvey, 2013), y que aspira a incidir en su planificación y conformación, tanto en el aspecto físico como simbólico.

De esta forma, la defensa del patrimonio se activa en distintos puntos del casco histórico de la ciudad: Cerro Alegre (defensa ex-cárcel pública), Cerro Concepción (defensa Paseo Atkinson), Cerro Playa Ancha (defensa Barrio Inglés), Borde Costero (oposición a construcción de torres de departamento) Muelle Barón (oposición a levantamiento de un mega centro comercial), y Barrio Puerto (oposición a construcción de supermercado). 
Como se ha sostenido, estos procesos de defensa patrimonial han provocado una conciencia ciudadana, la que sumada a nuevas corrientes teóricas han configurado lo que actualmente se denomina el derecho de acceso al patrimonio cultural. Este es entendido como la prerrogativa que tiene toda persona, individual o colectiva a "la capacidad de conocer, comprender, entrar, visitar, hacer uso, mantener, intercambiar y desarrollar el patrimonio cultural, y de beneficiarse del mismo, además de la creación de otros, sin impedimentos políticos, religiosos, económicos o físicos" (Tello, 2012:192).

No se trata solamente de un uso o beneficio, sino de participar protagónicamente en la toma de decisiones de su preservación y salvaguardia. De ahí la relevancia que ha ido adquiriendo el tema de los derechos culturales, en particular el derecho al patrimonio cultural, tal como se observa en un Informe Anual de Derechos Humanos en el cual se señala:

\footnotetext{
"La importancia de asegurar su vigencia es indudable en países como Chile, en los que se exhiben altas tasas de desigualdad. Se trata de derechos que tienden a garantizarles a las personas niveles de vida mínimamente dignos, por lo cual su inobservancia importa directamente una afectación a la calidad de vida de que pueden gozar los ciudadanos de un Estado" (Universidad Diego Portales, 2003:380).
}

En esta disputa son varios los elementos que entran en juego: las disposiciones legales que favorecen las iniciativas de la empresa privada en detrimento del respeto al patrimonio cultural, aspecto que el gobierno local y nacional promocionan al estar integrados bajo un sistema económico neoliberal; un segundo aspecto son las distintas visiones sobre la ciudad de Valparaíso, su pasado, presente y futuro, tanto desde la ciudadanía como desde el Estado, esto es, una ciudad imaginada; $y$ finalmente, la parcial y reducida implementación de un derecho humano en las políticas públicas culturales donde sólo las dimensiones técnicas y de divulgación forman parte de ellas, dejando sin presencia a la dimensión política del mismo, esto es, la participación expresa de los interesados en la toma de decisiones que afectan a su patrimonio.

\section{La continuidad de un conflicto y el liderazgo de una organización}

La defensa sistematizada y constante del patrimonio cultural de Valparaíso tiene un hito clave hacia mediados de la década de los noventa, cuando las distintas organizaciones sociales se articulan en torno a Ciudadanos por Valparaíso. Esta es una asociación paradigmática de la defensa patrimonial porteña, esencialmente por su carácter transterritorial, es decir, tal como se había señalado, no está inserta en algún barrio o zona determinada sino que actúa como un catalizador de la organización ciudadana. Quizás este es uno de los rasgos más novedosos de ella: el hecho de no estar anclada en un territorio específico, sino ser en sí misma un movimiento desencadenante de activación ciudadana en resguardo de los distintos lugares porteños.

Esta organización patrimonialista comenzó sus acciones en 1994 en torno al caso del edificio Luis Cousiño, inmueble patrimonial víctima de un incendio, cuyo propietario, por el alto valor del terreno, pretendía demoler. Posteriormente, el caso de la demolición del tradicional cine frente a la Plaza de la Victoria para convertirse en una tienda de una cadena comercial despertó la inquietud de la organización. Se puede desprender de estos ejemplos, la extensión y diversidad de temas que asume la organización patrimonialista, que en palabras de uno de sus líderes históricos lo reseña del siguiente modo: 
"Nosotros pensamos que era mejor varios conglomerados, varias organizaciones y siempre tuvimos la idea, en Ciudadanos por Valparaíso, que el conglomerado era Ciudadanos por... y después un nombre o una acción y en el Comité también, es la misma idea, Comité de defensa de... (...) de manera que si bien hay un logo que los reúne a todos, cada organización se preocupa de un problema. Entonces, Comité de Defensa del Atkinson, Comité de Defensa de Playa Ancha" (Juan, agosto, 2006).

Ciudadanos por Valparaíso representa un tipo de movimiento ciudadano contracultural, y en específico, contrapolítico, dado que sus integrantes se manifiestan críticos al sistema y los partidos políticos, pero están plenamente conscientes del rol político que juegan en la escena urbana: un contrapeso a las decisiones abusivas del poder político sea este procedente del gobierno central, o local, como asimismo de organismos empresariales. La tendencia de estos movimientos de defensa patrimonial urbano, tienen como principal propósito contrapesar el poder y estimular los procesos democráticos de participación ciudadana, generando a su vez conciencia cívica respecto de que todos somos dueños de la ciudad y corresponsables de ella: "porque hoy en día todos vivimos como si la ciudad fuera de otros y hecha por otros" (Juan, agosto 2006).

En diciembre del 2006, se inscriben como organización comunitaria funcional, lo que les permitió moverse con mayor legitimidad y autonomía en sus acciones políticas, legales y para su propia subsistencia. Pero, sin duda, la mayor externalidad positiva fue convertirse en un gran condensador de causas patrimoniales. $Y$, en ese sentido, una de sus líderes de ese período declaraba sus expectativas futuras:

"Yo creo que van a ir tomando más fuerza. [En el caso de] los vecinos de Playa Ancha, ellos ahora sienten que hay algo que no está andando bien, que ellos apostaron por un modelo y calidad de vida, etc., que sienten que agresivamente esto se puede transformar en otra cosa, ahora ellos sienten que pueden reaccionar y que pueden agruparse y pienso que eso es un super logro. No es esa como letanía de dejar hacer como era antes, como mira, aquí somos víctimas de un sistema, no, la gente se siente que es parte, que puede ser parte y que puede exigir, informarse, que puede pedir algunas cosas a la autoridad y que puede fundamentar lo que ellos quieren y que puede perseverar y eso al final es bueno" (Paz, octubre de 2006).

No obstante, y acorde a un imaginario que ha sido permanente en el problema patrimonial, esta organización ha recibido críticas por su conformación mayoritariamente de expertos, sin representatividad popular. Pero fue precisamente este juicio a priori, el que impulsó a Ciudadanos por Valparaíso a delinear una interesante forma de concertación estratégica con organizaciones territoriales, gremiales y populares; medida que les permitió en la acción cotidiana romper paradigmas tradicionales en torno a la idea del patrimonio, asesorando ya desde fines de la década de los noventa a numerosas organizaciones patrimoniales que nacían espontáneamente por los barrios porteños.

Estas estrategias y lineamientos estuvieron presentes a la hora de diseñar un segundo ciclo de activación patrimonial, reflejado en las campañas pro defensa patrimonial asumidas: Campaña contra instalación del supermercado Santa Isabel en el Barrio Puerto; Campaña por los Lugares Valiosos en defensa del comercio tradicional; Campaña "Que no nos tapen la vista" contra la edificación en altura en el borde costero; Campaña por protagonismo ciudadano en Ex cárcel pública, Campaña contra instalación del Mall en Muelle Barón. Dentro de los múltiples casos destaca el apoyo que prestó al Comité de Defensa de Playa Ancha, uno de los cerros más populares y tradicionales del 
puerto, y que repentinamente se vio amenazado por el levantamiento vertiginoso de torres de departamentos que obstaculizaban la vista que tenían los vecinos hacia el mar. Las palabras de Gonzalo, artista visual, y miembro de la resistencia patrimonial, dan cuenta de sus motivaciones y de la cotidianidad territorial del movimiento patrimonialista:

\footnotetext{
"Por lo tanto, este es un lugar privilegiado de Valparaíso, no solo por sus casas que son patrimoniales, sus casas inglesas que son residenciales y elegantes, sino también porque es aquí donde el puerto se enfrenta al abismo, es por aquí donde entra el viento de la ciudad y el viento es el hálito, entonces todos estos edificios en este lugar de Valparaíso y en todo lugar de Valparaíso son un desastre. Y fui a la casa del vecino de al lado que estaba desesperado por esta máquina y ahí empezamos a juntarnos todos los vecinos y formar un Comité de Defensa de Valparaíso, y fui nombrado presidente en el acto, sólo por haber llegado primero" (Gonzalo, octubre de 2006).
}

Y continúa su relato para explicar cómo nace la coordinación con Ciudadanos por Valparaíso:

\begin{abstract}
"Entonces dijeron que si ellos podían y tenían la experiencia, también nosotros, y yo llamé al Chino para ver cómo lo habían hecho. Como estas cosas son firmadas por personas hay que llegar a esa actitud, que los poderes son los poderes pero siempre hay alguien que firma y hay que relacionarse con las personas perfectas. Entonces ahí nos metimos con Ciudadanos por Valparaíso, personas con las que yo nunca había tenido contacto, que tienen una orientación (....) y empezamos a agrupar a las juntas de vecinos que para mí eran los responsables directos de que Playa Ancha se haya quedado sin protección" (Gonzalo, octubre de 2006).
\end{abstract}

Tal como señalábamos en el principio del texto, la capacidad de incidencia de esta organización se ha mantenido activa ininterrumpidamente, destacando en el último tiempo su lucha por el respeto a la fisonomía arquitectónica de la ex cárcel pública contra los planes municipales (rechazando incluso la donación del afamado arquitecto Oscar Niemeyer) y la necesidad de ser un espacio participativo para el ejercicio cultural de vecinos y porteños en general. La visión innovadora de Ciudadanos por Valparaíso se refleja en romper el cerco elitista que rodea a la idea patrimonial al involucrarse en estrategias territoriales y populares como lo fue su participación activa en los cabildos patrimoniales, y su vocación internacionalista al asociarse a la red de "Ciudades y territorios justos" trastocando totalmente la visión tradicionalista del patrimonio. Esta visión patrimonial se ha sostenido a través del tiempo y queda en evidencia actualmente en su rechazo a la construcción de un centro comercial en el borde costero, convocando a la ciudadanía bajo la consigna ¡NO al mall Barón!, con tal grado de legitimidad que fueron invitados a exponer tanto ante ICOMOS como en la misión oficial de UNESCO para la revisión del caso, que se inició por la denuncia de la propia organización ante autoridades locales, regionales y nacionales sin encontrar respuesta satisfactoria. En esta campaña es posible encontrar ciertas características que se distinguen de las anteriores, particularmente por el involucramiento de nuevos actores en la defensa de sus requerimientos, tales como organismos técnicos del patrimonio cultural del Estado chileno y de cooperación internacional. Asimismo, sobresale el despliegue de recursos comunicacionales como las redes sociales y periódicos ciudadanos, como también legales empleados en la exigibilidad de respeto hacia su patrimonio.

$\mathrm{Y}$, si bien es cierto, el conflicto puntual lleva ya una década, en los últimos tres años este movimiento de defensa patrimonial ha potenciado su presencia ciudadana obstaculizando y deteniendo las acciones que desde la Empresa 
Portuaria de Valparaíso (EPV) y la Municipalidad de Valparaíso se han desplegado en esa dirección. Para lograr este propósito las organizaciones ciudadanas, bajo el alero de Ciudadanos por Valparaíso, han recurrido al Consejo de Monumentos Nacionales, como órgano técnico encargado del cuidado y protección del Casco Histórico y el Muelle Prat, sitios declarados patrimonio de la humanidad que se ven afectados por el proyecto de la empresa portuaria. También han acudido, como ya se señaló, al Comité del Patrimonio Mundial de la UNESCO y al Comité Chileno del Consejo Internacional de Monumentos y Sitios ICOMOS Chile, ambas instancias de cooperación internacional destinadas a la supervisión del estado de conservación de los sitios y bienes declarados Patrimonio Mundial ${ }^{1}$.

Particularmente, las críticas a la iniciativa privada con apoyo estatal se orientan a la fragmentación que produce en Valparaíso en su condición de ciudad-puerto, carácter que, de acuerdo a los patrimonialistas, constituye parte central de la historia de la ciudad como el principal puerto del Pacífico y que la declaratoria confirma².

Junto a lo anterior, las críticas también apuntan a la ilegalidad de esa construcción desde el punto de vista técnico. Esto se debe a que una edificación de equipamiento mayor, como lo es este caso, no cumple con la Ordenanza de Urbanismo y Construcciones al no enfrentar una vía pública troncal o expresa y, también carece de un plan de evacuación en caso de tsunamis. Además, no cuenta con un plan de manejo patrimonial, considerando que posee en sus terrenos patrimonio arqueológico y una edificación Inmueble de Conservación Histórica, como lo es la Bodega Simón Bolívar. Se añade a lo anterior un antecedente no menor, como es la obligación contractual de EPV de pagar 21 millones de dólares por concepto de mantención de áreas verdes durante el período de concesión de los terrenos. Ante el escándalo que esto suscita en los habitantes de la ciudad, la sociedad civil ha llevado a interponer recursos legales en los tribunales, en la Contraloría General de la República y también han hecho parte al Ministerio de la Vivienda y Urbanismo, al Consejo Regional de Valparaíso, y del mismo modo, a la Comisión de Cultura de la Cámara de Diputados.

Como se evidencia a la luz de este caso, en la raíz del conflicto encontramos diversos conceptos y maneras de comprender a la ciudad de Valparaíso y su patrimonio cultural. Esta situación conduce a analizar y presentar el problema en torno a tres claves: la ciudad imaginada, el malestar ciudadano y el derecho al patrimonio.

\section{Valparaíso en claves: La ciudad imaginada}

Uno de los puntos centrales de este debate tiene que ver con las decisiones de la autoridad respecto a la proyección de Valparaíso, que está contextualizada indudablemente por la globalización y políticas neoliberales. La ciudad imaginada contiene tres marcos axiales: la ciudad patrimonial, con la declaratoria de la UNESCO; en segundo término ciudad-puerto con su actividad productiva histórica; y finalmente capital cultural, con la instalación de la sede nacional del Consejo de la Cultura. Cada una de ellas contiene una narrativa, que constituye fragmentos de lenguaje que nos permiten captar momentos de la vida social (Lindón, 2007). En este caso es una narrativa hegemónica, ya que hace referencia a la totalidad de la ciudad y de sus habitantes, desconociendo su diversidad cultural e histórica. Giandomenico Amendola, 
sociólogo y urbanista, problematizó gran parte del fin de siglo pasado la transformación del modelo de las ciudades y la instauración de una nueva ciudadanía desarrollada sobre la base de una narrativa de la ciudad, independiente del contenido complejo de sus habitantes:

\footnotetext{
"En un contexto de intensa competencia urbana en el mercado global, la imagen deviene estratégica en la lucha para atraer capitales, personas, empresas, y el imaginario es un factor decisivo para "vender" la ciudad y sus partes. La ciudad debe presentarse si no como ideal, por lo menos como la mejor posible para vivir, para producir, para competir. Con este propósito, tiene que seducir, convencer tanto emocionalmente como discursivamente: tiene que darse una imagen plausible y adecuada en función de un objetivo de mercado (el papel que la ciudad se propone desarrollar), un objetivo social (a quién se dirige) y tiene que enseñar su pasado y sus potencialidad (con qué argumentaciones)" (2000:292).
}

De esta manera, la ciudad real desaparece bajo una estrategia "de la apariencia", con esta se tiende a crear una ciudad imaginada que preceda, esté por encima y se adhiera a la ciudad real y material. En el caso de Valparaíso esta narrativa o relato se soporta sobre tres aspectos angulares.

\section{i) Ciudad puerto/ portal}

Se da inicio a este proceso de creación de ciudad hacia fines de la década de los noventa con la reconversión de uso del suelo de un tramo del borde costero del puerto de Valparaíso, que si bien en el origen correspondía a una demanda ciudadana por acceder a él ${ }^{3}$, en tanto espacio público, hoy en día está instalada como la decisión con mayor rechazo por los grupos ciudadanos, debido justamente al modelo neoliberal que predomina en la planificación para su acceso, que implica la futura construcción del mall y de un proyecto inmobiliario.

En la revisión de la trayectoria del cambio de uso de suelo, nos encontramos con que es un proyecto que forma parte del Plan Maestro vigente de la Empresa Portuaria de Valparaíso $(E P V)^{4}$, iniciativa que se diseñó y se comenzó a ejecutar desde principios de la década pasada y cuya finalidad perseguía tanto el desarrollo de la actividad portuaria como el posicionamiento de la ciudad en el plano nacional e internacional. De esta manera, la nueva gestión portuaria estableció definir zonas en el borde costero de acuerdo a su destino productivo. Los dos sectores extremos, el sector Yolanda-Barón por el norte, y el que va desde el Molo de Abrigo hasta la Caleta El Membrillo, por el sur (zonas 1 y 4), se destinaron a reserva portuaria, es decir, quedaron reservados para la ampliación de la infraestructura propia del puerto.

La zona 2, que media entre el sector de Barón y la calle Edwards del plan de Valparaíso, es la que se destinó a desarrollo urbano; a usos culturales, turísticos, recreativos o a servicios. Es el área que se integrará plenamente a la ciudad, y comprende unas 18 hectáreas. Esta es la zona del conflicto.

En la zona 3, que va desde la calle Edwards hasta el Molo de Abrigo -área que comprende parte de la zona de postulación correspondiente al Muelle Prat-, el uso será netamente portuario. Se contempla, sin embargo, un proyecto de remodelación del Muelle Prat que potencie su condición de atractivo turístico y centro recreacional de la ciudad. 
Figura 1: Emplazamiento Mall Puerto Barón en puerto de Valparaíso

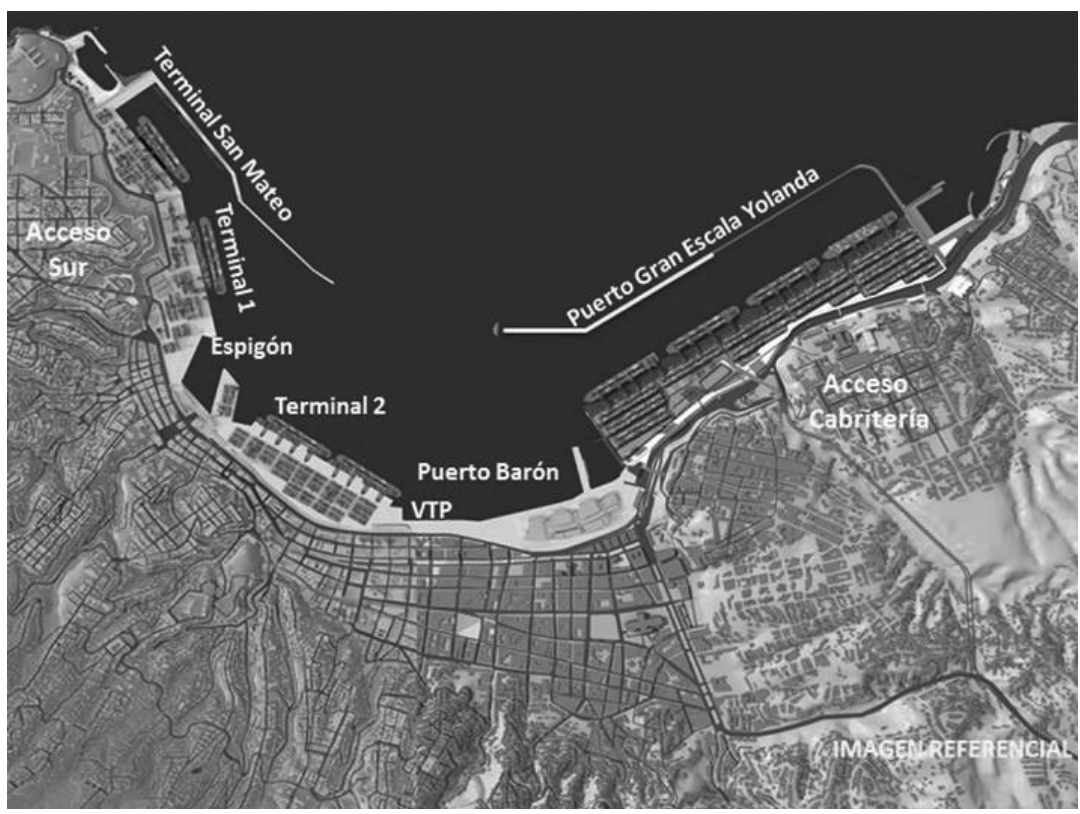

Fuente: Empresa Portuaria de Valparaíso

En la zona del conflicto ya se han realizado una serie de intervenciones que han ido ejecutando el plan original. Es así que en el año 2002 se lleva a cabo la transformación del Muelle Barón como un paseo de uso abierto a la comunidad porteña, constituyendo el primer hito de la apertura del Borde Costero.

Con posterioridad, otras acciones continuaron en esa dirección: se inauguró el espacio Puerto Deportivo en Paseo Muelle Barón, y también se abrió a la comunidad el Paseo Costanera, situado entre avenida Francia y Edwards, con 431 metros de extensión y emplazado en terrenos portuarios a lo largo del rompeolas.

Para lograr estos cambios que hicieron posible acceder al sector Barón, fue necesario trasladar la actividad portuaria al Sector de Placilla Antepuerto Curauma vía el Acceso Sur y camino La Pólvora, a cargo del Ministe- rio de Obras Públicas (MOP), permitiendo de este modo descongestionar a la ciudad del tránsito de camiones que lo utilizan. Es importante destacar que el empeño público-privado en sacar adelante este proyecto, se demuestra en el hecho que el presidente del directorio de EPV de la época era un flamante ex ministro de gobierno, quien anunciaba con toda seguridad que el proyecto estaría operativo a más tardar el año 20095.

En 2006, se entrega en concesión el proyecto de apertura y transformación del borde costero de Valparaíso, Puerto Barón, a la Sociedad Plaza Valparaíso S.A. En una primera instancia estos terrenos serían concesionados; con posterioridad y mediante la firma de un decreto presidencial en $2006^{6}$, la figura legal se amplió a la posibilidad de compraventa, agudizando, por lo tanto, el quiebre con la ciudadanía. 
Figura 2: Mapa proyecto Mall Puerto Barón

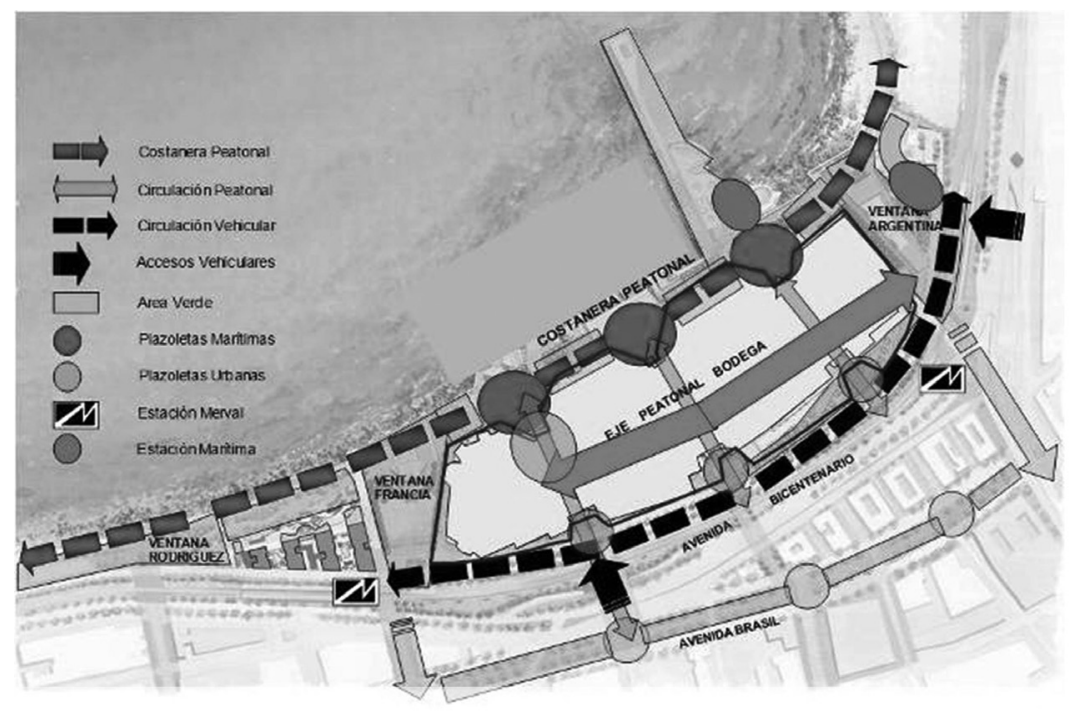

Accesibilidad y Espacios Públicos

Fuente: Empresa Portuaria de Valparaíso

La última de las acciones se realizó en abril de 30 años en régimen de concesión. Sin duda de 2013, cuando EPV adjudicó a la transnacional de origen español, OHL Concesiones Chile, el concurso para la explotación de la nueva esta operación sobre el sector 2 ha sido la de mayor notoriedad y la que levanta más escozor en la ciudadanía.

terminal 2 del Puerto de Valparaíso por un plazo

Figuras 3 y 4: Imágenes proyecto Mall Puerto Barón
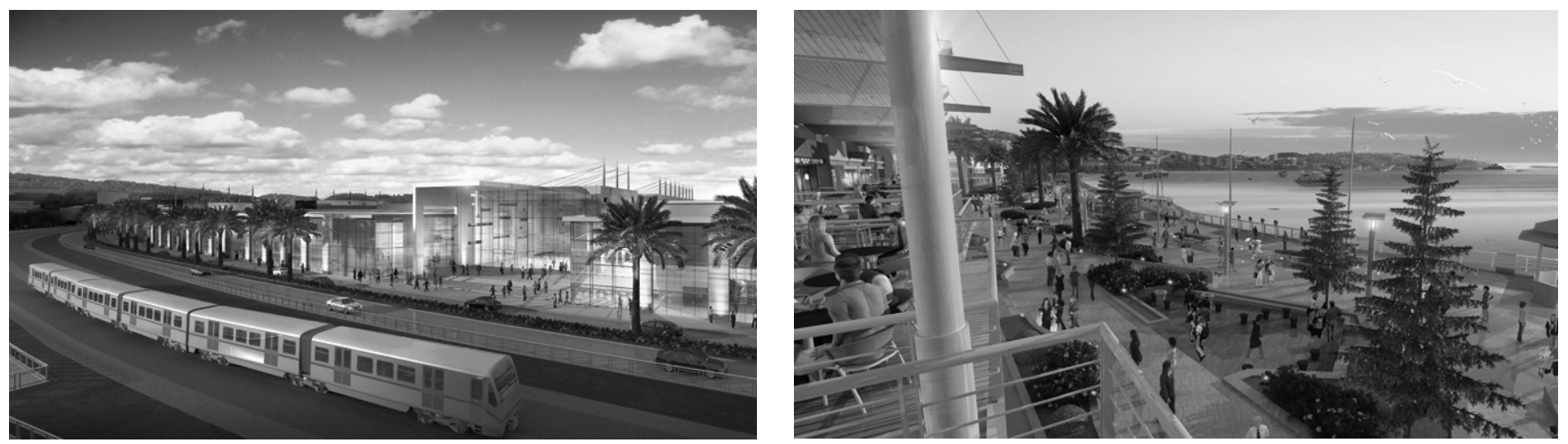

Fuente: Proyecto Puerto Barón. Sociedad Plaza Valparaíso S.A. 
En la vereda de enfrente, en cambio, se puede apreciar la visión positiva que presenta la empresa respecto de las bondades del proyecto. En su página web se detalla que Puerto Barón, "concebido desde sus inicios como un nuevo centro urbano" en el cual convergieran sectores comerciales con áreas verdes y recreacionales, corresponde a una etapa más en el cumplimiento de los anhelos de la ciudadanía de Valparaíso por acceder al borde costero. Con la licitación emprendida por la Empresa Portuaria de Valparaíso,

“(...) los habitantes de la ciudad recuperarían la relación directa con el mar, (...) además de contar con un nuevo polo de crecimiento económico, de atracción turística y de puestos de trabajo, los cuales, en definitiva, aportan al desarrollo y resurgimiento de la ciudad de Valparaíso".

Para la realización de su proyecto se diseñó la estrategia "buscando contribuir al progreso de Valparaíso respetando su identidad, patrimonio y visión de futuro". Si bien a EPV le corresponde la responsabilidad de la reconversión del uso de suelo del borde costero, en este proyecto no estaba mencionado que el Plan Maestro era parte de una estrategia de gran envergadura del gobierno central, destinada a instalar a Valparaíso como una ciudad que pudiese competir por las inversiones de las grandes empresas internacionales e insertarse en la corriente principal del turismo internacional. Con ese objetivo surge el Plan Valparaíso, propuesto por el gobierno del presidente Ricardo Lagos que en su mensaje del 21 de mayo de 2002 dirigido a la ciudadanía expone:

\footnotetext{
"Vivimos en la era de la globalización, mi deber como Presidente es trabajar para que Chile entre al mundo global, aprovechando al máximo sus oportunidades que se nos ofrecen, disminuir los riesgos y cuidar que los beneficios de esa globalización, se distribuyan equitativamente entre todas las familias".
}

Se proponía en dicha ocasión como proyecto Bicentenario para ser ejecutado entre los años 2001 y 2010. Junto con abrir la ciudad al mundo e instalarla como un portal de ingreso de capitales y personas, también estaba su consideración para postularla como Sitio de Patrimonio Mundial por la UNESCO, hecho que se concretó finalmente en julio de 2003.

\section{ii) Ciudad patrimonial}

Como se ha mencionado, esta iniciativa más que un fundamento cultural para las autoridades de la época, y en concordancia con visiones del patrimonio como un potencial producto (Nivón, 2010), tuvo como objetivo principal activar económicamente un territorio deprimido. Significa que, más allá del valor propiamente de sentido colectivo, hay un uso instrumental, funcional al sistema neoliberal y focalizado en la búsqueda de recursos para el desarrollo económico más que humano de los habitantes de la ciudad.

La ciudad patrimonial se fundamenta en aspectos de orden de trazado urbano, de arquitectura, como también geográfico y geomorfológico, siendo los elementos que darán cuerpo al expediente de postulación. Sin embargo, es importante señalar que la candidatura de Valparaíso no sólo apela como argumento de justificación para su nombramiento los elementos constitutivos y característicos del sector de postulación: el casco histórico y el sector del Muelle Prat, sino que a su vez, el valor excepcional se amplía y se extiende en el contexto general de la ciudad, dejando bajo ese manto a los diversos grupos que la componen y sus historias diversas. Este punto es fundamental para la comprensión del conflicto en estudio, por cuanto aquí radica una arista clave de su constitución: 
"Los valores patrimoniales de la ciudad están contenidos en ella como un todo, y no en un sector específico. En efecto, la diversidad de las soluciones arquitectónicas y urbanísticas, y el carácter multifacético de la ciudad, han determinado una delimitación del sitio que comprende varios sectores, cada uno de los cuales tiene un carácter particular. Las formas de relación entre estas diferentes áreas, y en particular las formas de relación entre el plan y el cerro, son también valiosas en sí mismas. Por otra parte, la ciudad de Valparaíso no tiene un centro histórico, en el sentido tradicional del término, sino que se desarrolló generando diversos núcleos, en un proceso dinámico" (Consejo de Monumentos Nacionales, 2001:4).

Destacan en la misma presentación, que el valor universal excepcional de Valparaíso está dado, entre otros aspectos, por la topografía de sus cerros que configuran un anfiteatro natural y la adaptación e integración de sus construcciones a esos contornos de suelo que hacen de ella una ciudad sin un único centro.

Se acostumbra a señalar o indicar que el valor universal y excepcional de esta ciudadpuerto descansa justamente en su condición de representar una globalización temprana durante el siglo XIX, convirtiéndose en el puerto más importante de la costa sudamericana del Pacífico, y eje clave en las comunicaciones y el comercio marítimo mundial (Cabezas, 2009). Sin embargo, el argumento que fundamenta la importancia y trascendencia patrimonial de Valparaíso se basa en otros aspectos que hablan de su heterogeneidad constitutiva, tanto de las procedencias de sus habitantes como en la forma de hacer ciudad, aspectos que definitivamente configuran su riqueza y valor excepcional y que exceden un perfil, un rasgo único y determinado.

La declaratoria, asimismo, trae consigo la obligación indefinida de la protección del sitio por parte del Estado que, a través de sus organismos técnicos y de administración local, debe formular un plan de gestión de conservación y protección del bien. Es importante tener en consideración que la protección y la gestión de los bienes declarados Patrimonio Mundial, deben garantizar que el valor universal excepcional y las condiciones de integridad y/o autenticidad en el momento de la inscripción en la lista se mantengan o mejoren en el futuro.

Las expectativas de desarrollo económico y social depositadas en esta declaratoria por la autoridad central y local no trajeron consigo los resultados esperados, ya que fueron insuficientes para lograr el impulso requerido, a pesar de los avances de la Estrategia de Desarrollo Regional. Esta situación lleva a crear una nueva instancia de crecimiento implementando el Programa de Recuperación y Desarrollo Urbano de Valparaíso (PRDUV) desplegado entre los años 2006 y 2012, también conocido como "Valparaíso Mío", impulsado por la Subsecretaría de Desarrollo Regional y Administrativo (SUBDERE) con financiamiento por parte del Estado mediante un crédito del Banco Interamericano de Desarrollo (BID). El objetivo de este programa era contribuir a la revitalización de la ciudad de Valparaíso, poniendo en valor el patrimonio urbano como fundamento de nuevas actividades económicas y sociales.

Paralelamente, se ve la necesidad de generar un programa que orientase sus esfuerzos hacia la conservación y protección del sitio declarado Patrimonio Mundial por UNESCO. Para cumplir con ese fin, se crea el Plan Director de Gestión Patrimonial (PDGP), iniciativa a cargo de la I. Municipalidad de Valparaíso y del PRDUV, con la meta de optimizar la gestión, administración y operación de la zona patrimonial y su sustentabilidad futura. 


\section{iii) Capital cultural}

El Programa de Recuperación y Desarrollo Urbano de Valparaíso (PRDUV) mencionado, también da surgimiento a una nueva estrategia para promocionar Valparaíso. Esta descansa en su condición de territorio que acoge a artistas visuales, literatos, poetas, y además le da un valor al hecho de considerarla cuna de la cultura popular urbana. Con estos atributos en su sitio web la ciudad de Valparaíso se promociona destacando su condición de capital cultural (ratificada en votación en Cámara de Diputados en mayo de 2003), la cual descansa en la particularidad de sus habitantes:

"Valparaíso inspira cultura. Genera sus propios artistas y acoge aquellos foráneos que se enganchan de la ciudad. Ser puerto internacional le significó absorber diversas costumbres y libertad creativa. Hoy es Capital Cultural de Chile por su histórica voluntad de expresión. Su geografía así lo dispuso, este gran escenario natural que llama al arte. (...) De Rubén Darío a Pablo Neruda; Mauricio Rugendas a Camilo Mori; pasando por el dibujante Lukas al fotógrafo Antonio Quintana, y esto por mencionar a algunos que ya son considerados clásicos".

$Y$ en cuanto a ser la ciudad que da origen a la cultura popular, en el mismo sitio se declara que:

"Durante las décadas del 50 y 60, la bohemia de estibadores y marineros en los bares míticos del Barrio Puerto, con sus valses y cuecas bravas, poesía etílica y de burdel, crearon la cultura popular de la ciudad. En los noventa, veinte pintores nacionales homenajearon su espíritu artístico con el Museo a Cielo Abierto que decora las calles del Cerro Bellavista. El cúmulo de esas cosas habla de una habitabilidad del arte- dice Luciano San Martín, a cargo de la Dirección de Desarrollo Cultural y Patrimonial de la Municipalidad. Una herencia que se va regenerando en nuevas expresiones, por ejemplo, en murales y graffitis que ya son postales de la ciudad".
Ciudad puerto/portal, Ciudad patrimonial y Capital cultural, los tres conceptos que sostienen la ciudad imaginada, no se han dado de manera sucesiva en el tiempo, es decir, no es que se haya tomado uno y luego se haya desechado por otro que tenga mayor impacto, sino más bien han coexistido sincrónicamente, apreciándose que la autoridad ha recurrido a ellos indistintamente durante estos últimos años dependiendo del aspecto que se quiera destacar. Pero es indudable que para las autoridades locales de Valparaíso, el sentido patrimonial responde a una lógica económica, teniendo al turismo como el eje articulador, tal como lo evidencia el Plan RUMBO, propuesta estratégica para convertir a Valparaíso en destino turístico y que se enmarca en el concepto de Ciudad Cultural y Patrimonial. Esta estrategia combina diversos elementos patrimoniales como un producto turístico, desde el arte y la poesía (Cerro Bellavista) hasta el potencial natural de los sectores Laguna Verde y Peñuelas, en las afueras de la ciudad, todos transversalizados por el polivalente concepto de "Alma Porteña".

\section{La segunda clave: malestar ciudadano}

Al observar con detenimiento las expresiones vertidas por los ciudadanos, vemos que la consigna representa la agudización del malestar de los habitantes por las decisiones de la autoridad respecto de los bienes patrimoniales colectivos que afectan su cotidianidad, su historia y su identidad, junto con tener la clara percepción de no ser incorporados en la toma de decisiones. Arturo Michell, economista y miembro de la organización Ciudadanos por Valparaíso señala que: 
"En ningún proyecto han escuchado la petición de los vecinos. Esperamos que se detenga la construcción del mall. La principal queja es que nunca se nos ha tomado en cuenta. Anuncian conversaciones pero nunca se ha consultado a nadie, los ciudadanos no somos dueños de nuestro destino. Basta que alguien de Santiago quiera hacer algún proyecto y eso pareciera ser la ley"7.

Estas expresiones evidencian lo planteado por Harvey (2008), en cuanto a los conflictos de poder que se desencadenan por el control de los espacios, y el surgimiento de la idea de derecho a la ciudad (Harvey, 2013), que evidentemente alude a que los ciudadanos tengan la potestad de incidir en las decisiones que los afectan y, resistir al modelo neoliberal de planificación urbana. $Y$ este hecho es el que se manifiesta en Valparaíso. Es una oposición derivada de la no inclusión de su opinión, de su parecer. Las maneras de conducir la participación ciudadana que se han llevado hasta hoy por los distintos gobiernos posdictadura, no han sido suficientes ni en la cantidad ni en la calidad de las mismas, y en la mayoría de los casos son conducidas por lógicas de rentabilidad de mercado, y no de calidad de vida para todos/as.

Este hecho queda de manifiesto tanto en la Ley de Municipalidades como en la norma sobre participación ciudadana, ya que reconoce la consulta pública pero con un carácter no vinculante. $Y$ respecto al plebiscito, en Valparaíso no ha sido una medida a la que la autoridad local haya acudido para encontrar una salida democrática. En una nota de prensa se hace alusión a lo sostenido:

\footnotetext{
"Por primera vez en Valparaíso un grupo de ciudadanos solicitó un plebiscito comunal vinculante al municipio porteño para poner en discusión la construcción del mall Barón, edificaciones en las alturas, estacionamientos subterráneos en plazas, cierre de colegios, entre otras materias. Esta acción legal que se estipula en la ordenanza municipal y que nunca había sido ocu-
}

pada por los porteños, cumple el rol de dejar decidir soberanamente a las personas sobre los proyectos que se construirán en la comuna"

Este reclamo en relación al derecho de participar en los asuntos de la ciudad no se reduce al conflicto por el Mall Puerto Barón. Ya en una investigación del año 2005 se deja en claro que la opinión de los ciudadanos es prácticamente inexistente y desfasada para la ejecución de un proyecto:

"El tema de la participación ciudadana resulta de poca
influencia en el desarrollo de los distintos proyectos. La
participación de los actores sociales aparece después
del desarrollo de los planes de los proyectos. Se tra-
ta de reuniones para discutir el proyecto, sin tomar en
cuenta sus observaciones. Por lo tanto, resulta que los
movimientos ciudadanos existentes no se sienten iden-
tificados con los proyectos que se están desarrollando,
sobre todo en el Sector Barón". (De Carlos et al., 2005).

El sentir ciudadano contrasta con los argumentos de las autoridades políticas que señalan que la Estrategia de Desarrollo Regional 20012010 sí contiene elementos de participación:

“(...) su formulación fue producto de un ejercicio amplio y participativo, coordinado por la Secretaría Regional Ministerial de Planificación y Coordinación. Se realizaron doce seminarios que fueron organizados por las universidades regionales, seis temáticos y seis territoriales, uno en cada capital provincial continental"'.

De igual manera sucede, por ejemplo, con la opinión de los altos directivos de la Empresa Portuaria de Valparaíso que se escudan en el hecho que el proyecto emana de un compromiso entre ciudadanos y autoridades establecido en el Cabildo de 1991, cuando se acordó reabrir el borde costero que fue cerrado por el crecimiento del puerto. Y, esgrimen además, como elemento participativo, los sondeos de opinión realizados por importantes empresas 
encuestadoras que en promedio registran más de un $70 \%$ de aprobación a favor de la iniciativa.

No obstante, lo que aquí se evidencia es una diferencia profunda no solo en los mecanismos formales de participación, sino esencialmente en la manera de ver el ejercicio ciudadano de la democracia. Para las autoridades y empresarios esta se reduce a unas cuantas reuniones y algunas encuestas contratadas por ellos mismos, mientras que los habitantes y vecinos de Valparaíso exigen y reclaman su derecho a imaginar y construir su ciudad.

\section{La tercera clave: el patrimonio como derecho}

La insuficiente acogida a la opinión de la ciudadanía ha llevado a las organizaciones de la sociedad civil a recurrir a instancias de la UNESCO como una manera de proteger la zona del borde costero, que se ve amenazada por la construcción del mall, arguyendo la pérdida o disminución del valor universal excepcional del sitio de patrimonio mundial y, que tanto el Comité del Patrimonio Mundial e ICOMOS, son los encargados de supervisar. Tal como se ha visto en los antecedentes expuestos esto sería en parte efectivo, porque los cambios propuestos para esa zona formaban parte del documento de postulación del sitio para la declaratoria.

De esta manera, las organizaciones patrimonialistas se han visto en la necesidad de organizarse para proteger el bien cultural. Esto se debe principalmente a que no existe un canal expreso que acoja las demandas que el derecho al patrimonio cultural y el derecho a la ciudad requieren, y en segundo lugar, a la falta de un cierto conocimiento sobre los derechos culturales y la exigibilidad de los mismos. No hay que perder de vista que cuando se acude a la UNESCO se recurre a una instancia que reconoce y da protección al patrimonio cultural y obliga a los Estados a su cuidado, no obstante, aquello no otorga derechos ni es una instancia de derecho internacional, por lo tanto, jurídicamente, las personas y los grupos quedan fuera de su competencia.

El académico José Llano, bajo esa mirada, expresa su parecer respecto del eventual daño patrimonial que provocaría el Mall Puerto Barón en Valparaíso y declara desconocer si las deficiencias y el incumplimiento de compromisos implicarán la pérdida de la cualidad de patrimonio mundial que hoy ostenta Valparaíso. Pero asegura que:

\footnotetext{
“(...) hoy por hoy Valparaíso es un tipo de laboratorio neoliberal, tanto cultural como político (...) la UNESCO debería permitirnos debatir primero. Ya lo estamos haciendo. Ojalá que sea lo mejor para esta ciudad, mi ciudad"10.
}

En general, los patrimonialistas usan como recurso para defender su ciudad leyes y artículos, tanto de la Constitución Política de la República como de derecho administrativo, la Ley General de Urbanismo y construcciones, entre otros. Sin embargo, no se hace uso intensivo de los derechos culturales, que están reconocidos y vigentes desde 1989.

En ese sentido, la Constitución Política del Estado en su artículo $5^{\circ}$ inciso $2^{\circ}$, reconoce y determina que "Es deber de los órganos del Estado respetar y promover tales derechos, garantizados por esta Constitución, así como por los tratados internacionales ratificados por Chile y que se encuentran vigentes". 
Como lo expresa Humberto Nogueira:

"Tal perspectiva promocional de los derechos fundamentales está expresamente contenida en la Constitución chilena en el artículo 5, por asegurar los derechos fundamentales en base, no sólo a la explicitación formal de los derechos asegurados constitucionalmente, sino también incorporando a éstos los derechos asegurados por las fuentes formales del derecho internacional. Lo trascendente es que el ordenamiento jurídico asegure los derechos sociales y sus instituciones garantizadoras administrativas y jurisdiccionales, como normas jurídicas vinculantes y de efecto directo al menos en su contenido esencial, además del contenido mínimo de tales derechos asegurado por el derecho internacional"(2009:145).

Es cierto que Chile sólo firmó en septiembre de 2009 el Protocolo Facultativo de los Derechos Económicos Sociales y Culturales ${ }^{11}$, y que aún no lo ratifica, aunque ello no lo licencia para que no sean exigibles y se den cumplimiento como la Constitución señala. El debate y la confrontación hablan del derecho al patrimonio cultural, sin embargo, nos encontramos que, por un lado, las dimensiones técnicas y de divulgación del derecho de acceso al patrimonio cultural abordadas por las políticas públicas culturales presentes hoy en día, son insuficientes para dar cuenta y acoger las peticiones de protección y respeto del patrimonio de los grupos organizados. Y por el otro, que dentro de la ciudadana todavía no hay conciencia suficiente de la exigibilidad sobre este derecho.

También es importante destacar que la cuestión patrimonial durante estos últimos diez años ha incrementado su influencia en la ciudadanía, excediendo el límite de los expertos (García Canclini, 1995), e involucrándola con temas referidos a la ciudad y su cotidiano vivir como asunto o problemática que afecta a todos los habitantes de ella. Particularidad que se debe, fundamentalmente, a que el patrimonio cultural arranca desde el sentir de las diversas subjetividades sociales surgido de sus memorias y biografías, que se proyecta en bienes tangibles e intangibles y que a su vez, otorga una auto imagen sólida y consistente de sí que opera a largo plazo, que es respetada y reconocida por los demás indistintamente en los diferentes campos de la sociedad dando sentido de continuidad a las vidas actuales, uniendo su pasado, presente y futuro.

\section{Conclusión}

A partir de los antecedentes expuestos se puede establecer que el patrimonio ha dejado su condición de Bien Cultural ennoblecido por el paso del tiempo, ajeno a las contingencias de la vida diaria y que, por el contrario, actúa como un activador de acción social y política (Prats, 2004). Esta situación ha ido consolidando una tensión entre concebir el patrimonio como un producto de mercado o como un recurso de resistencia sociocultural (Rojas Alcayaga, 2015). Sin descartar que ambas dimensiones coexistan sincrónicamente, esta tensión dialéctica provoca, al menos con certeza en Valparaíso, que el patrimonio cultural se constituya como un centro de disputa por el espacio urbano entre el poder público-privado, que proyecta su ciudad imaginada en los circuitos globales, y un imaginario social, entendido como un magma de significados (Castoriadis, 2010) que se construye cotidianamente por parte de los ciudadanos y, que articulan su defensa como un bien identitario y popular.

Las causas de la organización social en torno al patrimonio, ha sido el objetivo principal de este trabajo, porque es un hecho palmario el crecimiento del argumento patrimonial en el escenario urbano. Sin duda, los patrimonialistas forman parte de lo que Tilly (2010) denomina movimiento social, caracterizándoles como organizaciones esencialmente de índole local, y que trascienden la política formal. Por eso, si bien ha sido Valparaíso el escenario elegido para analizar este 
fenómeno debido a su carácter de ciudad-patrimonio, es el evidente poder de influencia que han alcanzado los movimientos patrimonialistas en la discusión por el modelo urbano de desarrollo lo que ha orientado este artículo.

¿Puerto o enclave turístico? ¿Recurso del capital o capital cultural? Estas disyuntivas parecen desplegarse en el imaginario del poder público-privado, y del emergente poder ciudadano que lo edifica subjetivamente (Varela, 2005), pero no por ello sin rigor político. Por el contrario, los movimientos patrimonialistas pretenden resguardar uno de los principales bienes patrimoniales intangibles de Valparaíso, sostenido en la propia declaratoria patrimonial, su carácter de ciudad símbolo de la cultura popular, pero de aquella no etiquetada en postales, sino la que surge de la profunda cultura de resistencia que caracteriza, precisamente, a la cultura popular (Martín-Barbero, 2004).

Son diversas organizaciones patrimonialistas las que han sido capaces de aglutinar desde el mundo popular hasta asociaciones profesionales bajo este objetivo, sinergia que les ha permitido ejercer con mayor presión sus demandas ante autoridades locales, nacionales e internacionales. Aspecto que asimismo ha contribuido a que los conflictos denunciados alcancen importantes grados de visibilidad en distintos medios de comunicación. Además, han logrado fragmentar el férreo apoyo a las ideologías modernizantes en los sectores políticos, logrando apoyo a sus causas de algún sector de concejales de la ciudad, como de la Comisión de Cultura de la Cámara de Diputados y de órganos colegiados (Andueza \& Aravena, 2013)

$E$ indudablemente, dentro del conjunto de movimientos "Ciudadanos por Valparaíso" conforma un interesante paradigma de esta fortaleza creciente de los movimientos patrimonialistas, no solo por la continuidad temporal y sistemática de sus luchas, sino esencialmente por el enfoque innovador a los problemas de la ciudad, uniendo a las históricas contradicciones materiales las nuevas dimensiones culturales o postmateriales (Birnbaum, 2003), que permiten resignificar el sentido de ser ciudadanos del siglo XXI. En este nuevo contexto sociocultural el derecho a la ciudad y el patrimonio se erigen como derechos exigibles e irrenunciables, tal como lo demuestra esta organización porteña articulando defensas patrimoniales por veinte años. Nacida al fragor de la polémica por el futuro de la llamada "ratonera" (Palacio Cousiño), lideró la icónica campaña "Que no nos tapen la vista", pasando por la oposición a la construcción de un supermercado en Barrio Puerto, la campaña "Lugar valioso", la demolición de los almacenes fiscales en el puerto o la destrucción arquitectónica y expropiación social de la ex cárcel pública, hasta la férrea negativa a la construcción de un centro comercial en el sector Muelle Barón en la actualidad $^{12}$. ¿Qué es lo que une todas estas reivindicaciones? Sin duda una certera valorización y defensa de los bienes patrimoniales, pero desde nuestra perspectiva el mayor mérito es una convicción y prisma que es capaz de desafiar a las propias concepciones tradicionales del patrimonio cuando su líder expresa respecto a la posible ampliación de actividades portuarias: "Nosotros preferimos un puerto lleno de camiones que transiten por las calles, que llenar los cerros de Valparaíso de hoteles boutiques" (Paz, mayo 2015).

Desde esta perspectiva entonces, el patrimonio cultural se constituye en una toma de conciencia de nuestro lugar en el mundo y del poder que, como sujetos formados socialmente, adquirimos para modificar y transformar la misma sociedad en la que nos desenvolvemos y constituimos, ampliando y fortaleciendo las capacidades de incidencia a favor de la profundización de la democracia y del incremento de los niveles de bienestar humano.- 


\section{Notas}

${ }^{1}$ El Centro del Patrimonio Mundial recibió una carta firmada por 24 instituciones locales (universidades, sindicatos y la sociedad civil) y 1.000 habitantes de Valparaíso, en contra del desarrollo de bienes raíces y proyectos turísticos en la zona patrimonial de Muelle Prat. El Centro del Patrimonio Mundial ha solicitado información al Estado respecto del caso. En noviembre de 2012, la compañía privada Mall Plaza solicitó una reunión para presentar el proyecto Puerto Barón ante la UNESCO. Disponible en http://whc.unesco.org/fr/soc/1916 Fecha de consulta: 15 junio 2013.

${ }^{2}$ El Consejo de Monumentos, anfitrión de la comisión revisora, explicó por medio de una minuta publicada en su sitio web las razones de la vista de los revisores. "El objetivo de la evaluación es determinar si los proyectos en curso podrían tener impacto negativo sobre los atributos por el cual fue declarado el sector del Área Histórica de la Ciudad-Puerto de Valparaíso e identificar alternativas para asegurar la protección adecuada del sitio". Publicado 28 noviembre 2013 en www.eldesconcierto.cl Fecha de consulta: 19 de mayo 2014.

${ }^{3}$ En el Cabildo Abierto realizado en Valparaíso en 1991, se expresó la aspiración por acceder al borde costero, aunque fuera en forma parcial. Desde ahí surge el debate por definir a Valparaíso como Ciudad - Puerto. A comienzos del 2000, nace la idea de desarrollar Puerto Barón, entonces EPV comienza a estudiar e implementar el Proyecto, tras el mandato político que dio el Gobierno a su Directorio. Luego de esto, en el año 2006 se adjudica el desarrollo del proyecto a la empresa Plaza Valparaíso S.A.

${ }^{4}$ La Ley de Puertos de 1981 terminó con la Empresa Portuaria de Chile (EMPORCHI), órgano estatal que administraba eficientemente los puertos de Chile, y que bajo el argumento de una modernización portuaria vio reducido su accionar, hasta el punto que en la década de los noventa 27 puertos nacionales, entre ellos Valparaíso queda-

\section{Referencias bibliográficas}

Amendola G. (2000). La ciudad postmoderna. Madrid: Editorial Celeste.

Andueza, P. \& Aravena, P. (2013). Valparaíso Reclamado. Demandas ciudadanas de la ciudad - puerto. Valparaíso: Perseo Ediciones.

Aravena, P., Cataldo, B., Contreras N., \& Villanueva, A. (2006). Trabajo, memoria y experiencia. Fuentes para la historia de la modernización de Valparaíso. Valparaíso: CEIP Ediciones.

Birnbaum, N. (2003). Después del progreso. Reformismo social estadounidense y socialismo europeo en el siglo XX. Barcelona: Tusquets.

Cabezas, Á. (2009). "Valparaíso Profundo: patrimonio ciudadano". Revista del Colegio de Arquitectos de Chile № 139.

Calderón, F. (2009). "Los movimientos socioculturales en tiempos de inflexión". En Movimientos sociales en América Latina. Ambien- ron en manos de la empresa privada, naciendo en 1998, la Empresa Portuaria de Valparaíso (EPV) (Aravena, 2006).

${ }^{5}$ Germán Correa en El Mercurio de Valparaíso sábado 7 de octubre de 2006.

${ }^{6}$ Decreto 144 de la Ley 19.300 art.10 firmado por la presidenta Michelle Bachelet. Dictamen 33426 de la Contraloría General de la República, 30 de mayo de 2013. Disponible en: http://www.contraloria.cl/LegisJuri/DictamenesGeneralesMunicipales.nst/DetalleDictamen?OpenForm\&numero=33426\&ano=13 Fecha de consulta: 13 junio 2014

${ }^{7} \mathrm{http}: / /$ radio.uchile.cl/2013/06/01/mall-muelle-baron-registra-nuevas-denuncias-por-dano-patrimonial-en-el-puerto

${ }^{8}$ Ciudadanos de Valparaíso solicitan plebiscito comunal para discutir construcción de mall Barón, publicado en www.biobiochile. cl, 28 de enero 2013.

${ }^{9}$ Estrategia de Desarrollo Regional 2001-2010. Publicado por SUBDERE, 2001.

10 "Valparaíso: Patrimonio de la humanidad en peligro". Publicado en El ciudadano, 24 de Octubre de 2013

${ }^{11}$ El Protocolo Facultativo permitirá, por primera vez, que las víctimas busquen justicia a nivel internacional por violaciones a sus derechos económicos, sociales y culturales, mediante el envío de comunicaciones individuales al Comité de los Derechos Económicos, Sociales y Culturales (DESC). Así, representa un verdadero hito en el sistema internacional de derechos humanos". - Mensaje de la Alta Comisionada de las Naciones Unidas para los Derechos Humanos, Navi Pillay, durante la ceremonia de apertura a firma del Protocolo Facultativo. Nueva York, 24 de septiembre de 2009.

${ }^{12}$ La misión secreta del ciudadano Michell en París en contra del Mall Barón. Disponible en: http://www.anin.cl/nota/67/3698/misi\%C3\%B3n-secreta-del-ciudadano-michell-paris-contra-del-mall-bar\%С3\%B3n Fecha de consulta: 23 de diciembre 2014

talismo, feminismo, pueblos originarios y poder empresarial. Buenos Aires: Siglo XXI.

Carrión, F. (2005). "El centro histórico como proyecto y objeto de deseo". EURE 93: 89-100.

Castells, M. (2004). Movimientos sociales urbanos. México, DF: Siglo XXI.

Castoriadis, C. (2010). La institución imaginaria de la sociedad. Buenos Aires: Tusquets.

García Canclini, N. (1995). Culturas híbridas: estrategias para entrar y salir de la modernidad. Buenos Aires: Sudamericana.

Garretón, M. A. (2002). "La Transformación de la acción colectiva en América Latina". Revista de la CEPAL, 76: 7-24.

Harvey, D. (2008). La condición de la posmodernidad. Investigación sobre los orígenes del cambio cultural. Buenos Aires: Amorrortu. (2013). Ciudades rebeldes. Del derecho a la ciudad a la revolución urbana. Madrid: Akal. 
Lindón, A. (2007). El constructivismo geográfico y las aproximaciones cualitativas. Revista de geografía Norte Grande, 37: 5-21.

López-Morales, E., Gasic, I. \& Meza, D. (2012). "Urbanismo pro-empresarial en Chile: políticas y planificación de la producción residencial en altura en el pericentro del Gran Santiago". Revista INVI 76: 75-114.

Márquez, F. (2007). "Imaginarios urbanos en el Gran Santiago: huellas de una metamorfosis". Eure 99: 79-88.

Martín-Barbero, J. (2004). Oficio de cartógrafo. Travesías latinoamericanas de la comunicación en la cultura. Buenos Aires: Fondo de Cultura Económica.

Nivón, E. (1989). "El surgimiento de identidades barriales. El caso de Tepito". Anuario Alteridades: 31-44.

Nivón, E. (2010). "Del patrimonio como producto. La interpretación del patrimonio como espacio de intervención cultural". En Gestionar el patrimonio en tiempos de globalización: México, DF: Universidad Autónoma Metropolitana.

Nogueira, H. (2009). "Los derechos económicos, sociales y culturales como derechos fundamentales efectivos en el constitucionalismo democrático latinoamericano". Revista Estudios Constitucionales 2: 143-205.

\section{Documentos en línea}

Centro de Derechos Humanos Universidad Diego Portales (UDP): Informe Anual sobre Derechos Humanos en Chile 2003. Disponible en: http://www.derechoshumanos.udp.cl/informe-anual-sobre-derechos-humanos-en-chile-2003/. Fecha de consulta: 12 de agosto 2013.

Consejo de Monumentos Nacionales (CMN): Postulación de Valparaíso como Sitio del Patrimonio Mundial UNESCO. Segunda serie N 70, 2004, Primera edición. Disponible en: http://www. monumentos.cl/consejo/606/articles-45668_doc_pdf.pdf. Fecha de consulta: 28 de junio 2014.

De Carlos, P., Piwonka, E., Ruiz, J.C. \& Welz, J. Plan Valparaíso. Reconversión del borde costero Primer semestre 2005. Publicado en Plataforma Urbana http://www.plataformaurbana.cl/archive/2006/01/12/ plan-valparaiso-reconversion-del-borde-costero/. Fecha de consulta: 21 de marzo 2014
Pérez, C. (2013). "Los gobiernos neoliberales trasladan la responsabilidad estatal de la gestión y producción cultural hacia las empresas". Revista PH Instituto Andaluz del Patrimonio Histórico, 84: 222-223.

Prats, L. (2004). Antropología y patrimonio, Barcelona: Ariel.

Rojas Alcayaga, M. (2015). Dialéctica del patrimonio. Modernizaciones y cultura activa en disputa. México DF: Los lirios-UAM.

Salazar, A. (2006) ."Democracia cultural y los movimientos patrimonialistas en México". El patrimonio cultural en la era de la globalización Acercamiento, problemática y perspectivas. Cuicuilco, 38: 73-88.

Tilly, C. (2010). Los movimientos sociales, 1768-2008. Desde sus orígenes a Facebook. Barcelona: Crítica.

Tello, L. (2012). El derecho al patrimonio común de la humanidad: origen del derecho de acceso al patrimonio cultural y su disfrute. México: Comisión Nacional de los Derechos Humanos.

Universidad Diego Portales (2003). Informe Anual sobre Derechos Humanos. Santiago: UDP.

Varela, R. (2005). Cultura y poder. Una visión antropológica para el análisis de la cultura política. Barcelona: Anthropos.

Empresa Mall Plaza. Proyecto Puerto Barón. http://www.proyectopuertobaron.cl/portada-interior/antecedentes-de-mall-plaza. Fecha de consulta: 13 de marzo 2014.

Subsecretaría de Desarrollo Regional (SUBDERE VALPARAÍSO): Estrategia Regional de Desarrollo. Región de Valparaíso. Marzo 2001. http://www.subdere.gov.cl/documentacion/valpara\%C3\%ADso-periodo-2001-2010-estrategia-regional-de-desarrollo-regi\%C3\%B3n-de-valpara\%C3\%ADso . Fecha de consulta: 25 de marzo 2014.

UNESCO Instructivo de intervención "Zona Típica Área Histórica de Valparaíso" Sitio de Patrimonio Mundial V Región de Valparaíso Chile 2001. http://www.unesco.org/culture/natlaws/media/pdf/ chile/chil_instructivo_valpo_spaorof.pdf. Fecha de consulta: 15 de marzo 2014. 